\title{
A review of rehabilitation of low vision patients
}

\section{OA Oduntan*}

\author{
Discipline of Optometry, School of Physiotherapy, Sport Science and Optometry, Faculty of Health \\ Sciences, University of KwaZulu Natal, Private Bag X54001, Durban, 4000 South Africa
}

< oduntanoa@ukzn.ac.za>

Received 6 August 2008; revised version accepted 9 December 2008

\begin{abstract}
It has been estimated that in 2002, there were about 124 million people worldwide who had low vision $^{1}$. These people have best visual acuity (VA) ranging from worse than $6 / 18$ but equal or better than $3 / 60$ in the better eye after treatment and or standard refraction. In terms of visual field (VF), they have VF loss of less than 20 degrees in the better eye with best possible correction ${ }^{2}$. Low vision may result from congenital or acquired diseases, trauma, uncorrected refractive error or other ocular disorders. Although such people may be amenable to medical or surgical interventions, they may be assisted to maximize their remaining vision by using optical, non-optical or electronic devices or combinations of these. Illumination control or environmental modifications may also assist. As a result of the low vision, the patient may have social, psychological, economic and other related problems which need to be addressed along with
\end{abstract}

the visual problems. For effective rehabilitation of the low vision patient therefore, a multidisciplinary team approach needs to be employed. In this approach, professionals from a number of disciplines are independently involved in the assessment and management of the patient. The purpose of this review article is to highlight the importance of a multidisciplinary approach to low vision rehabilitation, the various professionals and their roles that may be involved in the rehabilitation of the low vision patient. This article will increase knowledge of rehabilitation of patients with low vision and may improve the services offered to such patients.

Key words: Low vision, Visual disability, Rehabilitation, Psychological problems, Handicap.

\section{Reference}

1. Resnikoff S, Pascolini D, Etya'ale K, Pararajasegaram R, Pokharel G, Mariotti SP. Global data on visual impairment in the year 2002. Bull World Health Org 2004 82 844-851.
Low vision is a condition in which the visual acuity and visual field that a person has cannot be improved medically, surgically or by standard refraction to VA of $6 / 18$ or better or visual field of $\geq 20$ degrees in the better eye ${ }^{2}$. The prevalence of low vision is likely to increase significantly because the percentage of elderly people, who are most often afflicted with low vision, is increasing ${ }^{1}$. As a result of low vision, the patient would have difficulty performing many Activities of Daily Living (ADL) and would require rehabilitation programme. Rehabilitation in relation to health care has been defined as a process of helping handicapped individuals move from positions of dependency toward positions of independence in a community of their choice ${ }^{3}$ and this definition applies to low vision rehabilitation. The rehabilitation of a person with low vision requires a programme which involves a holistic consideration of the person's social, economic and psychological needs rather than concentrating only on his or her visual needs.

Low vision can affect the quality of life of the person who has the condition. It has been reported that 
most patients would benefit from rehabilitation processes provided by the low vision service and would thus be able to improve their Quality of Life (QoL) ${ }^{4}$. Such programmes rely on an interdisciplinary team of professionals or para-professionals to provide an effective service. The various professionals who could be part of the vision rehabilitation team include the optometrist, ophthalmologist, psychologist, psychiatrist, audiologist, social worker, occupational therapist, special educator, orientation and mobility instructor, reading specialist, visual therapist and physiotherapist. The role of each of these professionals is briefly discussed in this article.

\section{Optometrist}

Low vision care with respect to optometry is a relatively new but rapidly growing field of eye care. According to Stelmar ${ }^{5}$, the use of low vision devices which include telescopes and microscopes to enhance vision was not discussed in the ophthalmic literature until 1910. A team approach, utilizing the rehabilitation medicine approach has been advocated by Massof et $a l^{6}$ and is still being developed ${ }^{5}$. The optometrist is part of a rehabilitation team concerned with helping the visually impaired patient functioning to his or her full potential. The optometrist is often the first professional that the low vision patient contacts in the rehabilitative team and he or she is involved with the visual assessment, diagnosis of the cause and the degree of visual disability.

Although, there may be no possibility of reversing the visual impairment of the low vision patient, the person with the condition can return to an active, productive, rewarding and independent lifestyle with low vision devices and rehabilitation training ${ }^{7,8}$. For instance, a person who otherwise may not be able to move around independently due to visual impairment may be able to do so after undergoing a visual examination, provision of a telescope and appropriate mobility training. A person who is not able to read personal mail due to reduced vision, and had to depend on others for this task may on acquiring a magnifier (spectacle, hand or stand) of appropriate power and training be able to read such post independently. Also, a student who suddenly becomes visually impaired and therefore, is not able to continue his or her studies may be able to resume such studies after acquisition of relevant optical and/or electronic devices and training in their use. Furthermore, a person may lose his or her job as a result of low vision. With appropriate low vision devices, training and counseling, he or she may be able to secure another job. Optometrists therefore, have a great role to play in the rehabilitation of the low vision patient.

With regard to optometry, rehabilitation includes educating the patient about low vision, referral to community resources, teaching the client how to eccentrically view and read more effectively, the use of both optical and non-optical assistive devices and in some cases sensory substitution ${ }^{9}$ for ADL. It has been reported that improvement in both near and distance vision activities would improve daily functioning and remove barriers to $\mathrm{ADL}^{10}$.

Many people with low vision are frustrated because they can no longer engage in simple activities such as reading their letters while others feel socially isolated because they can no longer travel independently as they used to. Therefore, vision rehabilitation for patients with low vision can involve a range of services depending to a large extent on the degree of vision loss ${ }^{11}$. The services required may include programmes for independent living, the provision of assistive devices and training programmes, low vision therapy, orientation and mobility training, and creation of job opportunities for the visually impaired ${ }^{11}$. Some of these activities can be provided by the optometrist.

Once the patient has been referred to such a program, it is the duty of the multidisciplinary rehabilitation team to ensure the cooperation and active participation of the patient in the entire rehabilitation process $^{12}$. Rehabilitation strategies for patients have been considered to be functional, goal or attitude oriented $^{3}$. The functional oriented strategy consists of providing the patients with assistive technology, teaching them the alternative strategies and recommending environmental modifications with the aim of helping them to achieve specific behavioral goals ${ }^{7}$. The goal oriented strategy, in turn consists of assisting the patient to engage in specific behavioral activities (such as reading the newspaper) that the patient wants to perform but no longer can because of visual impairment ${ }^{7}$. With regard to low vision, the functional and goal-oriented strategies are within the domains of the optometrist. The optometrist may also be able to provide some attitude-oriented strategies, but this 
is particularly within the domain of psychologists or psychiatrists.

Referral to other professionals, services or resources is one of the roles of the optometrist. Although optometry training includes caring for patients with low vision, not all optometrists engage in low vision care and therefore an optometrist may refer a low vision patient to another optometrist for further care. Depending on the ocular clinical findings, the optometrist who engages in low vision care may refer the low vision patient to other professionals. In certain cases, referral should take place before the optometric management is commenced because the assessment, treatment and rehabilitation outcome of one professional can influence the activities of the other. For instance, referral to the ophthalmologist for active disease management should be done before optometric services are commenced, otherwise the use of low vision devices may not be successful. Also, low vision, like other disabilities is frequently associated with psychological, social and economic consequences; therefore patients with the low vision should be seen as a whole person having ranges of physical and psychological needs ${ }^{13}$. Therefore, if there are indications of serious emotional reactions as a result of the vision loss, the patient may need to be referred for psychological management before optometric management. The optometrist also refers the low vision patients to other relevant services, particularly social services, orientation and mobility training, applications for financial assistance such as transport subsidies and disability support, if the eligibility criteria are met ${ }^{14}$.

A major role of the optometrist is to prescribe appropriate low vision optical, electronic or non-optical devices which would enable the patient to achieve certain functional goals. Following the establishment that the patient is a low vision patient and absence of a need for a referral, the optometrist would examine the patient. The conventional pattern of basic vision assessment generally includes case history, visual acuity measurement, refraction (objective and subjective), ocular health evaluation, visual field, colour vision and contrast sensitivity. This is followed by functional visual assessment in which the low vision devices that the person requires to perform desired tasks are determined. These could be optical or electronic devices for distance and or near. The power of the device/s and the distance where each device will be used have to be determined. Quite often, a low vision patient would benefit from optical, electronic and non-optical devices; therefore more than one device may need to be prescribed.

Successful low vision rehabilitation involves more than prescribing low vision devices as it includes provision of instruction, training, and supportive services to enhance the patient's performance in the ADL ${ }^{15}$. Whatever device that is prescribed for the patient, an appropriate training in their use has to be provided otherwise the patient will not benefit maximally from the devices. Further, a follow-up visit will have to be scheduled to ensure that the patient is complying with the mode of use, is using and benefiting from the devices. For many low vision patients, the provision of appropriate level of illumination can mean the difference between being able or unable to perform a visual task $\mathrm{k}^{16}$. The optometrist is also involved in the illumination control processes; hence they prescribe relevant filters and educate the patient on the appropriate level of illumination that will enhance their visual performance. Coloured filters are able to contribute substantially to rehabilitation of low-vision patients; they can lead to improved VA, contrast sensitivity function (CSF) for all frequencies; reduction in glare sensitivity, reduction of photophobia, eye-strain and eye discomfort ${ }^{17}$.

The optometrist is also involved in educating and advising the patient on the limitations of his vision. For instance he or she informs the patient if the vision does not meet the legal limits such as for driving ${ }^{14}$. Even when a patient does not benefit from assistive devices, the optometrist still has a role to play ${ }^{14}$. He or she may play an important but relatively minor role in the vision rehabilitation of patients with severe visual impairment, especially those with significant visual field loss. Referrals for counseling and social support are vital to assist such patients to manage their visual handicap. Practical assistance to help overcome their limitations in ADL is then more likely to be accepted ${ }^{14}$.

Optometrists also play a role in establishing a low vision patient's eligibility for rehabilitation, educational and recreational activities as the information from the eye examination has a role in establishing a patient's eligibility for both rehabilitation and education involvement ${ }^{3}$. The optometrist therefore, can initiate the access to these facilities. People with low 
vision are usually apprehensive of going blind and this may result in emotional consequences. In this regard, the optometrist counsels the patient to help him or her to understand the present visual status, possible prognosis and what opportunities are available for low vision care. It is essential to let the patient know that there may be no cure for his or her eye condition, but that low vision care can assist in using remaining vision to a certain degree and a comprehensive rehabilitation process would improve his or her quality of life.

\section{Ophthalmologist}

The ophthalmologist's role in eye care is fundamentally one of treatment, restoration, prevention and provision of information about the condition, its prognosis as well as referral for rehabilitation ${ }^{18}$. The ophthalmologist is, therefore involved in examining the patient and establishing the etiology of the low vision. He or she is also involved with the management of the pathological ocular conditions that may require medication or surgical intervention. He or she also decides the stability or otherwise of the ocular disease. This is an important decision as optometric low vision care may not commence until there are indications that the eye or systemic disease resulting in low vision has stabilized. The ophthalmologist is also involved with the recommendation of the patient for registration as a low vision patient and informing the patient about the nature of the disease and motivate them to start low vision care in order to improve their quality of life.

In some countries, only the ophthalmologist can recommend a patient for registration as a low vision patient. The ophthalmologist may also provide some education to the patient regarding the level and limitation of his vision and what services are available for rehabilitation. A few ophthalmologists may also be involved in prescribing optical, non-optical and electronic devices to low vision patients, but in most cases, patients are referred to an optometrist for provision of optical and non-optical devices. It has been reported that ophthalmologist can help improve the QoL for the patient with age-related macular degeneration by treating the patient and providing referral for psychiatric care for depression, especially if symptoms are persistent ${ }^{19}$.

\section{Psychologist and psychiatrist}

Low vision can be a traumatizing experience, depending on several factors such as severity, suddenness, duration of the vision loss, the economic status, age and attitude of the person. For instance, a sudden vision loss can lead to emotional reaction such as shock and denial, which can eventually lead to depression $^{20}$. Low vision can leave a person anxious, depressed, confused or even fearful of his or her surroundings ${ }^{7}$. The depression associated with low vision may be because the person can no longer partake in the activities that he or she used to do such as vocational, educational, recreational and social activities and Activities of Daily Living (ADL). The common incidence of depression among people with visual imapirment has been associated with impaired visual and physical functions ${ }^{21}$. With loss of vision, a person finds that he or she has lost one of the main sensory organs and is no longer as independent as previously. In addition, loss of vision may sometimes result in loss of a job. Disability, handicap and frustration associated with visual impairment, therefore are often associated with psychological problems. The inability to perform ADL, decreased QoL and the reported increase in economic burden among this population may also be some of the reasons for the depression ${ }^{21}$.

It has been reported that persons with low vision have a higher probability of concentration problems during reading and entertainment, losing interest and enjoyment in their activities, feeling fatigued, irritable, sad, and tearful; having less hope for the future and wishing for death ${ }^{22}$. Karlsson ${ }^{23}$ reported an association between visual impairment and perceived low level of happiness in life, difficult periods or crisis and symptoms of distress such as depression, sleeping difficulties and tiredness, intrusive thoughts especially about vision, isolation and loneliness, worries and tension, distress about economic conditions, poor health attribution and depressive feelings. It has been proposed that, since attitudes are culturally determined, the loss of vision may threaten a person's integrity ${ }^{24}$.

Beaty ${ }^{25}$ hypothesized that visual impairment may lead to feelings of inadequacy and inferiority which may result in self-concept deficit. In a similar study, Obiakor and Stile ${ }^{26}$, however, did not find such selfconcept deficit among adolescents with visual im- 
pairments. It is, therefore, possible that self-concept deficit is not a general finding among individuals with visual impairment. The difference may be related to the environment in which an individual finds himself. For instance, a low vision patient who works among other low vision patients is less likely to exhibit a work-related negative self-concept, but another patient who works among normally sighted individuals may exhibit such a concept, especially if the co-workers are critical of him or her. A psychologist or psychiatrist can therefore be of help in cases where there is an associated psychological manifestation of poor self concept.

Low vision and loss of ability to perform ADL result in decline of quality of life (QoL) ${ }^{27-31}$. The deterioration in QoL has been associated with increase in the degree of visual impairment (VI) ${ }^{29}$ and presumably may also be a consequence of the economic burden that has been associated with visual impairment. The presence or absence of psychological problems may be influenced by personality factors, severity and type of onset of the condition. The nature of the condition such as suddenness, gradual and steadily deteriorating, or fluctuating may elicit emotional reactions. For the visually impaired persons not to suffer psychological disorders, the person should positively adapt to the new situation using positive strategies such as acceptance, trust, positive avoidance, minimization and control ${ }^{32}$.

When low vision patients show exacerbating emotional or psychological reactions, their rehabilitation will not be complete without the assistance of a clinical psychologist, psychotherapist or a psychiatrist who will deal with such problems, which have to be dealt with along with the visual problems. The visually impaired persons need psychological support at two levels in the rehabilitation process: the emotional level and the level of coping with daily activities ${ }^{32}$. These two levels of support are provided by the psychologist or psychiatrist whose modes of operation include counseling or psychotherapy. Some psychologists are involved in skills training for the low vision patients ${ }^{32}$. Visually, impaired children and adolescents and their families are at a high risk for maladjustment and distress, and in such cases, the psychologists can help in parent-child problems solving interactions in the families ${ }^{33,} 34$.
Attitude oriented strategy of rehabilitation is mainly in the hands of the psychologist and psychiatrist and may involve helping the patient to adjust psychologically to the limitations imposed by the impairments and this may involve counseling the patient to surrender unrealistic goals, learn to accept the current situation and face the challenges imposed by the visual impairment ${ }^{7}$. They need to be assisted in gaining a new perspective, to re-evaluate their goals, and to accept the challenges imposed by the visual impairment. Also, people with low vision need counseling in order to have hope for the future in spite of the current changes in their visual status. They need to be informed that there is a possibility of improvement in their quality of life, in spite of their reduced vision. In view of the various psychological factors associated with low vision, the psychologist and psychiatrists are important components of low vision rehabilitation.

\section{Audiologist}

In Dual Sensory Impairment (DSI), visual disability is associated with hearing loss; hence the audiologist may be involved in low vision rehabilitation. DSI may present at any age as a result of genetic defect, accident, injury, disease or environmental insults $^{35}$. This condition has wide range implications for physical and psychological functioning and quality of life ${ }^{35}$. In Usher's syndrome, a genetic condition, retinitis pigmentosa is accompanied by hearing loss ${ }^{36}$. With hearing loss, subjective refraction may be difficult. Hearing may be aided by modern electronic aids or hearing assisted telephones. The problems encountered by individuals with DSI are considerably greater than the effects of vision impairment or hearing impairment alone, because when these two sensory impairments are combined, the individual is seriously deprived of compensatory strategies that make use of the non-impaired sense ${ }^{37}$. Cochlear implant can play a significant rehabilitative role in patients with severe hearing loss and visual impairment ${ }^{38}$.

About two-thirds of patients with age-related macular degeneration (AMD) have visuomotor and balance deficits resulting in clumsiness and increased risk of falls. Visual, vestibular and somatosensory functions in balance control can be rehabilitated by training. This may result in a significant improvement for the vestibular input and fixation stability in- 
cluding postural sway, pointing accuracy and reading performance ${ }^{39}$.

\section{Social worker}

Low vision can lead to loss of jobs or inability to secure employment, therefore having social and economic implications. The implication for the patient in terms of job, pension et cetera must be considered. Also, the effects of visual performance on dependency relationships and family role have to be kept in mind. While the immediate situation must be dealt with, the patient's long term adjustment to his or her disability is often more important ${ }^{20}$. Therefore, a social worker may be needed for counseling and to search for an appropriate alternative employment. Also, the social worker can play an important role in both the evaluation and treatment of the patient with low vision. Social workers can participate in the psychosocial assessment, and help assess the client's coping and adaptation to the vision loss ${ }^{9}$. Vision impairment has been associated with depression ${ }^{40}$. An important role for the social worker in rehabilitation is to provide referral for counseling services. The social worker is also knowledgeable about community and government resources as well as potential financial assistance. Providing guidance and education about these issues may lead to more effective adaptation and coping with the vision impairment ${ }^{9}$.

People with low vision need hope and need to know that their quality of life can improve, even though their vision is not as good as it used to be. They need to be informed of how adaptive devices and low vision services can help them use remaining vision more effectively. In addition, their families need to be informed about how they can support their loved ones with low vision ${ }^{8}$. The social worker can effectively play this role. Also, the social workers can guide the patient through the rehabilitation process by way of encouraging the patient, particularly when he or she needs to try tasks or activities which are new or threatening or for which the person has low confidence. Also, assisting job seekers with disabilities to find jobs is an important part of rehabilitation ${ }^{41}$. The social worker can also assist in the assessment of whether or not the devices prescribed for the patient is being used.

Counseling may be required before some patients will accept referral or advice regarding practical solu- tions to overcome their limitations in $\mathrm{ADL}^{9}$. Assistance with ADL and counseling can also be provided too by the social worker. Therefore, a multi-disciplinary approach to the management of low vision and blindness should include the social worker.

\section{Occupational therapist}

Occupational therapy as a profession entered the field of low vision rehabilitation only recently, being preceded by orientation and mobility (O\&M) specialists, low vision therapists, and teachers of the visually impaired $^{12}$. OTs started working in LVR in the United States some time after 1990 and a similar situation subsequently developed in Canada with a handful of OT practitioners applying $\mathrm{LVR}^{12}$. Occupational therapy offers a programme that specializes in the treatment of people with low vision ${ }^{12}$. Restoring and maintaining the ability of the low vision patient to function independently through the use of specific interventions is an intricate process that calls for the collaboration of various health care professionals and occupational therapists (OTs) are essential members of the multidisciplinary rehabilitation team providing such interventions ${ }^{12}$. The role of the occupational therapist includes determination of the cognitive, psychosocial, and physical needs of the client. The evaluation process allows the occupational therapist to evaluate visual and non-visual client factors, history, roles, physical environment, and occupational performance ${ }^{31}$. Based on the evaluation, the therapist will design a vision rehabilitation program to teach the client how to function more effectively in ADLs in spite of the vision loss ${ }^{31}$.

In low vision rehabilitation, OTs can enhance performance of specific ADL by training skills that are dependent on residual vision such as reading and writing. They also conduct environmental assessments in the home and in the workplace or school to improve and promote a safe environment for patients with low vision $^{12}$. The OTs may also assist in developing rehabilitation programs for orientation and mobility, driving, and vision rehabilitation therapy ${ }^{12}$. When there is a difficulty in coping with daily living activities, the occupational therapist has to train the patient on alternate methods, in the use of assistive devices, modify environment and educate the patient and the family on coping strategies ${ }^{42}$. This approach may lead to increased level of independence, improved safety, 
increased adequacy of performance and decreased difficulty and increased satisfaction ${ }^{42}$. Also, OTs may be involved in the assessment, recommendation and provision of assistive devices and instructing people in the use of the devices in solving the patient's specific vocational, avocational and functional problems $^{42}$. During the occupational therapy evaluation, two parameters of activity, namely safety and independence are emphasized ${ }^{43}$. This will help the patient perform ADL independently and safely. Management of lighting, contrast, and glare are also critical roles of the therapist. The occupational therapist may need to refer the client to the low vision optometrist if he/ she finds that the client may benefit from low vision devices or the prescribed optical, non-optical or electronic devices are not as effective as desired. In addition, the occupational therapist may assist where a patient requires training in the use and adjustment to the optical devices and non-optical devices ${ }^{43}$. For a new employment, there is usually a need for training in the use of the various equipments in the workplace to ensure independence and safety, and this training may be done by the OT.

\section{Special educators}

The eye is an important organ for learning as a large proportion of what a child learns is via the eye and the visual system. Children who are visually impaired are potentially at a great disadvantage academically unless a special educational system is provided. Many children with visual impairment receive education at specialized schools for the blind where, besides the core curriculum, they are taught adaptive skills ${ }^{44}$. Special educational system requires special teachers and special learning materials as well as necessary environmental modifications. The partially sighted children need teachers who understand their visual limitations and demands and who have the special knowledge required for their social and educational circumstances and needs ${ }^{44}$. Children who are blind and/or visually impaired must be allowed to learn compensatory skills to achieve therapeutic goals. Development of these skills can be accomplished most effectively when these children receive services from qualified specialists in a team setting ${ }^{45}$. Special educators are specifically trained to meet the social, educational and developmental needs of children with various types of disabilities. These teachers occupy an important position in the rehabilitation process of the children as they are usually the link between the child and other rehabilitation professionals.

\section{Orientation and mobility (O\&M) instructor}

Orientation and mobility (O\&M) is a set of skills that allow persons with visual impairments to move safely efficiently and gracefully, know their location and remain orientated in their environment during travel $^{44}$. These skills are taught by O\&M specialists ${ }^{44}$. The orientation and mobility instructor is an important professional in the rehabilitation of the visually disabled. Many low vision patients do not need orientation and mobility, there are, however, a few who may need such training. The OM instructor teaches the low vision and blind persons how to move around freely in their environment, by introducing them to certain landmarks in the environment which they then use for navigation. An important aspect of orientation and mobility training may be in cases of those with severe peripheral field loss, therefore need training in environmental navigation. The O\&M instructor may also train the person in performing certain ADLs in the environment. This rehabilitation process is necessary each time a visually disabled patient locates into a new environment such as new school, new work place or new accommodation and helps to minimize the frustration associated with the visual loss with regard to environmental navigation.

\section{Physiotherapist}

There are a variety of ways in which vision modulates locomotion in a feedback manner ${ }^{46}$. Vision loss affects primarily stability aspect of gait, reducing the patient's ability to modify gait in response to obstacles in the environment. Also, visual inputs are an important source of information for postural control ${ }^{46}$. Balance has been shown to be more impaired with greater visual impairment which could result in fall and injury ${ }^{47}$ and visual impairment has been reported to increase the risk of fall ${ }^{48}$. These highlight the importance of physiotherapeutic role in the rehabilitation of the visually impaired.

Physiotherapy can contribute to both the assessment and intervention programmes of the visually impaired. Motor development and associated postural reactions will be trained, abnormal postures prevented or decreased, and body image and use of residual vision developed. Selection and supervision of devices 
and play equipment, as well as decreasing of physical handicap are also included in the physiotherapist's role in helping the child and his family ${ }^{49}$. It has been recognized that motor training programmes such as balance, coordination, strength, visuomotor control, and finger dexterity improved skills of children with low vision ${ }^{50}$. Children with low vision have some useable vision and learning to use the available vision depends on proper rehabilitation including physiotherapy management ${ }^{50}$. Children and elderly with visual impairment can therefore benefit from motor training provided by the physiotherapist. Since visual impairment may increase risk of falling, the physiotherapist will also be helpful in caring for the visually impaired persons who sustain injury as a result of falling due to visual impairment.

\section{Reading specialist}

Acquired low vision presents numerous challenges to the affected person, for many, it is difficulty with reading ${ }^{51}$. Reading is a major desire of many low vision patients. Many want to read newspapers while others wish to read religious books such as the bible. Unfortunately, even with necessary devices, reading with low vision requires more efforts than needed by the normally sighted persons. Also, reading with low vision requires certain compromises such as reading at a very short distance such as $25 \mathrm{~cm}$ or even closer. Low vision affects many aspects of reading, for instance, it is usually associated with a decreased reading speed, even when the optimum reading size is used ${ }^{52,53}$. The person with low vision may require a higher or lower than normal level of illumination for reading, depending on the etiology of his or visual condition. He or she may need to turn the book upside down and read from right to left due to visual field defect and may require the use of electronic adaptive devices such as the closed circuit television (CCTV). These require special training and a reading specialist may be quite helpful ${ }^{20}$. A considerable variation has been observed in the results of studies in reading performance of people with visual impairment and this has been attributed to several factors. According to Leat and Woodhouse ${ }^{54}$ these factors include whether eye movements are required to scan along a line of print, whether the text is scanned across a CCTV screen, size of the print relative to acuity, whether unrelated words or continuous text is used, and pathology of the group studied and experience of the subject. A reading specialist is required where there are indications of difficulty in achieving the desired reading ability with prescribed devices.

The type of optical devices employed for reading also affects the process of reading. Compared to ordinary reading (without magnification), one might expect magnification of the text and the limited reading field to give rise to difficulties when reading with the aid of a magnifier. In view of the above, a reading specialist needs to be involved in the rehabilitation of the low vision patient.

\section{Low vision therapist}

Low vision therapy is one of the most recent developments in the area of low vision care and also the most difficult to describe ${ }^{43}$. The Certified Low Vision Therapist (CLVT) works as part of an interdisciplinary team with an ophthalmologist or optometrist who provides low vision care. The CLVT performs functional low vision evaluation relating to activities of daily living, educational and vocational pursuits, leisure, social activities, access and participation in community programmes, coping ability and impact of the vision disability on other relevant people ${ }^{55}$. He or she uses functional vision evaluation instruments to assess visual functions such as visual acuity, visual fields, contrast sensitivity function, color vision, stereopsis, visual perceptual and visual motor functioning as well as literacy skills in reading and writing, as they relate to visual impairment and disability ${ }^{55}$. $\mathrm{He}$ or she trains the use of specific visual motor skills such as the identification and use of preferred retinal locus for fixation, accurate saccades, and smooth pursuits as well as the use of appropriate environmental modifications such as positioning, organization, illumination control and marking. The CLVT also educates the family of the visually impaired and other relevant persons on the functional implications of vision and refers patients to other professionals in the rehabilitation team ${ }^{55}$.

\section{Success of rehabilitation services}

A successful rehabilitation programme may reduce the rehabilitation demand by reducing the level of difficulty associated with the goal or task and/or by reducing the value assigned to the goal or task ${ }^{7,8}$. Effective rehabilitation processes can make a lot of 
difference in the quality of life (QoL) of the low vision patient. Following an evaluation of the effectiveness of a multidisciplinary low vision rehabilitation, in which first time low vision referrals were assessed before and after 3-6 months rehabilitation, significant improvements were found in the impact of impairment score, reading, accessing information and emotional well being ${ }^{48}$. This confirms that effective low vision rehabilitation can greatly improve the quality of life (QoL) of the low vision patient. It is incumbent on those providing rehabilitation of the disabled persons to measure the effectiveness of such care ${ }^{56}$. QoL is an important outcome used in the evaluation of rehabilitation provided to individuals ${ }^{56-58}$. Improvement in QoL is often given as a major goal for therapy ${ }^{58}$. The factors that have been used for defining QoL in relation to rehabilitation include social utility or the opportunity to fulfill valued social roles including work, emotional states such as happiness, satisfaction with one's own life conditions, achievement of personal goals and normal life measure by comparing current status to either pre-health or pre-illness condition ${ }^{58}$.

In low vision rehabilitation, clinical outcomes such as visual acuity in relation to visual performance achieved with the low vision devices or the usage of the devices have been used in the evaluation of low vision rehabilitation. Task performance such as the ability to read television titles or newspaper texts and questionnaires on low vision devices satisfaction rates have also been used ${ }^{59}$. There is currently a strong case for using a wide range of outcome measures which should include task performance (ability to perform certain ADL) and a measure of psychological adjustment to visual loss ${ }^{60,61}$ in addition to vision specific measures.

\section{Conclusion}

Effective rehabilitation of the low vision patient demands that a multidisciplinary approach be used. This implies that all relevant professionals should be involved in the rehabilitation of the patient. When necessary, every professional involved in the rehabilitation should involve other relevant ones so that the desired level of rehabilitation can be achieved. With this approach, the frustration that is inherent in low vision can be avoided and a better quality of life can be enjoyed by the patient.

\section{References}

1. Resnikoff S, Pascolini D, Etya'ale K, Pararajasegaram R, Pokharel G, Mariotti SP. Global data on visual impairment in the year 2002. Bull World Health Org 200482 844-851.

2. International statistical classification of diseases and related health problems, 10th revision Vol 1: Diseases Tabular List. Geneva: World Health Organization, 1992.

3. Emener WG, Hollingsworth DK. (Eds). Critical issues in rehabilitational counseling. Springfield. IL: Charles C Thomas, 1984.

4. Walter, Altihouse R, Humble H, Smith W and Odom JV. Vision rehabilitation: recipients' perceived efficacy of rehabilitation. Ophthal Epidemiol 200714 103-111.

5. Stelmark J. Emergence of a rehabilitation medicine model for low vision service delivery, policy and funding. Optom 200576 318-326.

6. Massof RW, Dagneli G, Deremik JT DeRose JL, Suleiman SA, Glasner NM. Low vision rehabilitation in the US health care system. J Vis Rehab 19959 3-25.

7. Massof RW. A systems model for low vision rehabilitation I. Basic Concepts. Optom Vis Sci 199572 725-736.

8. Kupfer C. The low vision education programme: Improving quality of life. Optom Vis Sci 199976 729-730.

9. Scheiman M. Low vision rehabilitation. A practical guide for Occupational therapist. New Jersey: Professional Books, 2007.

10. Lamoureux EL, Pallant JF, Pesudovs K, Rees G, Hassell JB and Keefe JE. The effectiveness of low vision rehabilitation on participation in daily living and quality of life. Invest Ophthalmol Vis Sci 200748 1476-1482.

11. Lovie-Kitchin JE, Whittaker SG. Prescribing near magnification for low vision patients. Clin Exp Optom 199982 214-222.

12. Markowitz M. Occupational therapy intervention in low vision rehabilitation. Can J Ophthalmol 200641 340-347.

13. Nguyen NX, Weisemenan M, Trauzettel-klosinski S. Spectrum of ophthalmologic and social rehabilitation at the Tübinger low vision clinic: A retrospective analysis of 19992005. Ophthalmol 2008105 563-569.

14. J E Lovie-Kitchin, J Devereaux, S Wells, K. Multi-disciplinary low vision care Clin Exp Optom 200184 165-170.

15. Bairstow M. Low Vision: Social and rehabilitation needs. Optician 1998216 18-21.

16. Hill S, Write M. Lighting for low vision: The office environment. Optician 1999217 28-32.

17. Rosenblum YZ, Zak PP, Ostrovsky MA, Smolyaninova IL, Bora EV, Dyadina UV Trofimova NN, Aliyev AGD. Spectral filters in low-vision correction. Ophthal Physiol Opt 200020 335-341.

18. Hoover RE. The ophthalmologist's role in new rehabilitations patterns. Trans Am Ophthalmol Soc 196765 471492.

19. Tasman W, Rovner B. Age-related macular degeneration: treating the whole patient. Can J Ophthalmol $200540389-$ 391.

20 Mehr BE, Freid AN, Mehr HM. Psychological and sociological factors. In: Mehr BE and Freid AN, eds. Low Vision Care. Chicago, Professional Press. 1975, Pp 13-24. 
21 Heyman KJ, Kerse NM, La Grow SJ, Wouldes T, Robertson MC, Campbell AJ. Depression in older people: Visual impairment rating of health. Optom Vis Sci 20784 1024-30.

22 Mojon-Azzi SM, Souza-Posa A, Mojon DS. Impact of low vision on well-being in 10 European Countries. Ophthalmologica 2008222205212.

23. Karlsson JS. Self report of psychological distress in connection with various degrees of visual impairment. $J$ Visual Imp Blindness 199892 483-491.

24. Taylor RE, Upton LR. Stress and coping: Implication for visual impairment. J Vis Rehab 19882 22-28.

25. Beaty LA. Adolescent's self concept as a function of vision loss. Adolesc 199227 707-714.

26. Obiakor FE, Stile SW. Enhancing self concept in students with visual handicaps. J Vis Impair Blind 198983 255-257.

27. Grover LL. Strategy for developing an evidence-based transdisciplinary vision rehabilitation team approach to treating vision impairment. Optom 200879 178-188.

28. Aspinall PA, Johnson ZK, Azuara-blanco A, Montarzino A, Brice R, Vickers A. Evaluation of quality of life and priorities of patients with glaucoma. Invest Ophthalmol 200849 1907-1915.

29. Esteban JJ, Martínez, MS, Navalon PG, Serrano OP, patiño JR, Purón ME, Martínez-Vizceaíno V. Visual impairment and quality of life: gender differences in the elderly in Cuenca, Spain. Qual Life Res 200817 37-45.

30. Cochrane G, Lamoureux E, Keeffe J. Defining the content for a new quality of life questionnaire for students with low vision (the impact of vision impairment on children. Ophthal Epidemiol 200815 114-120.

31. Okamoto F, Okamoto Y, Hiraoka T, Oshika T. Vision-related quality of life and visual function after retinal detachment surgery. Am J Ophthalmol 2008146 85-90.

32. Madu SN. Psychological factors associated with visual disability. A literature review. S Afr Optom 200463 109-119.

33. Burlingham D. Some problems of ego development in blind children. Psychoanal Study Child 196520 194-208.

34. Ammerman RT, van Hasselt VB, Hersen M. Parent-child problem-solving interactions in families of visually impaired youth. J Ped Psychol 199116 87-101.

35. Brennan M, Bally SJ. Psychosocial adaptations to dual sensory loss in middle and late adulthood. Trend Amplif 2007 11 281-300.

36. Otterstedde C R, Spandau U, Blankenagel A, Kimberling W J, Reisser C. A new clinical classification for Usher's syndrome based on a new subtype of Ushers's syndrome type I. Laryngoscope 2001111 84-6.

37. Saunders GH, Echt KV. An overview of dual sensory impairment in older adults: perspectives for rehabilitation. Trends Amplif 200711 243-258.

38. Takasaki K, Kanda Y, Kumagami H, Yashida H, YamamotoFukuda T, Miyamoto I, Takahashi H. Cochlear implantations in visually impaired patients. Euro Arch Otorhinolaryngol 2007264 363-367.

39. Radvav X, Duhoux S, Koenig-Supiot F, Vital-Durand F. Balance training and visual rehabilitation of age-related macular degeneration patients. J Vestib Res 2007 17 183-193.

40. Rovner BW, Casten RJ, Tasman WS. Effect of depression on vision function in age-related macular degeneration. Arch Ophthalmol 2002120 1041-1044.
41. Fabian ES and Waugh C. A job development efficacy scale for rehabilitation professionals. J Rehab 200167 42-47.

42. Holm M, Rogers J and James A. Interventions for daily living. In Crepeau EB, Corn ES, and Boyt SB. Willard and Spackman's occupational therapy. Philadelphia: Lippincott, Willaims and Wilkins, 2003 pp 494-661.

43. Moore M. Multi-disciplinary low vision care. Optician 1994 208 24-27.

44. Balashova Y. First orientation and mobility teacher preparation programme in Russia. Intern Congr Series 20051282 789-792.

45. Kern T. Barbier AC, Feist N. Integrated rehabilitation for the visually impaired, physically challenged children. Intern Congr Series 20051282 179-183.

46. Shumway-Cook A, Woollacott MH. Motor control: Theory and practical applications. Williams \& Wilkins. Baltimore: 1995.

47. Lee HKM, Skudds RJ. Comparison of balance in older people with and without visual impairment. Age and Aging 200332 643-649.

48. Lamoreux EL, Chong E, Wang JJ, Saw SM, Aung T, Mitchell P, Wong TY. Visual impairment, causes of vision loss and falls: The Singapore Malay Eye Study.

49. Sykanda AM, Levitt S. The physiotherapist in the developmental management of the visually impaired child: Care, Health and Development 20068 261- 270.

50. Aki E, Atasavun S, Turan A and Kayihan H. Training motor skills for children with low vision. Percept Mot Skills 2007 104 1328-1336.

51. Bower AR Reid VM. Eye movements and reading with simulated visual impairment. Ophthal Physiol Opt 199717 392-402.

52. Krischer CC and Meissen R. Reading speed under real and simulated visual impairment. J Vis Impair Blind 198377 386-388.

53. Legge GE, Pelli DG, Rubin GS, Schleske MM. Psychophysics of reading: Low Vision. Vision Res 198525 239-252.

54. Leat JL and Woodhouse JM. Reading performance with low vision aids: relationship with contrast sensitivity. Ophthal Physiol Opt 199313 9-6.

55. Academy for certification of vision rehabilitation and educational professionals. Low vision therapist certification handbook. Arizona 2007.

56. Day H. Quality of life: Counterpoint. Can J Rehab 19936 135-142.

57. Andresen EM, Meyers AR. Health-related quality of life outcomes measures. Arch Phys Med Rehabil 200081 Suppl 2 S30-S45.

58. Ferran H. Conceptualization of quality of life in cardiovascular research. Progr Cardiovas Nurs 1992 2-6.

59. Harper R, Doorduyn K, Reeves B, Slater L. Evaluating the outcomes of low vision. Ophthal Physiol Opt 199919 3-11.

60. Dodds AG, Bailey P, Pearson A, Yate L. Psychological factors in acquired visual impairment: The development of a scale of adjustment. J Vis Impair and Blind 199185 306310.

61. Dodds AG, Flannigan H, Ng L. The Nottingham adjustment scale: A validity study. Int J Rehab Res 199316 177-184. 